\title{
Learning Object Standards in Education: Translating Economy into Epistemic Atomism
}

Francis Lee

Linköping University Post Print

N.B.: When citing this work, cite the original article.

This is an electronic version of an article published in:

Francis Lee, Learning Object Standards in Education: Translating Economy into Epistemic Atomism, 2011, Science as Culture, (20), 4, 513-533.

Science as Culture is available online at informaworld ${ }^{\mathrm{TM}}$ :

http://dx.doi.org/10.1080/09505431.2011.605923

Copyright: Taylor \& Francis (Routledge)

http://www.routledge.com/

Postprint available at: Linköping University Electronic Press

http://urn.kb.se/resolve?urn=urn:nbn:se:liu:diva-53612 


\title{
Learning Object Standards in Education: Translating Economy into Epistemic Atomism
}

\author{
Francis Lee \\ Department of Thematic Studies, Linköping University \\ 58183 Linköping \\ francis.lee@liu.se
}

\begin{abstract}
In the early 2000s a technological standard for modular learning material, so called Learning Objects (LOs), was developed by a group of organizations and individuals. The vision behind developing this technical standard was to put online courses together as a jigsaw of independent 'off the shelf' pieces could be found in a database and assembled as you pleased. Using a computer program, it would be possible to choose the desired materials and join them into a course. In this standardization process, the chief problem of online education was argued to be high production costs and LOs were performed as a means to lower these costs by achieving economies of scale. Furthermore a technical method, modularization of LOs, was proposed as a means to achieve this aim. It was argued that modularization would be more efficient if course content was broken into 'packages' with small 'granularity'. The economic purpose was, as Actor-Network Theory would put it, translated into technological design. Additional translations put into play links between modularity/granularity and the treatment of LOs as 'atomic'. Atomic LOs were to be self-contained, non-sequential, and contextless digital objects. Last, in an extreme argument by one of the key proponents, LOs were performed as being the road to a new atomic science of education. By enacting Learning Objects in this manner a specific materiality of learning was composed which was geared toward what I call 'epistemic atomism': the performance of knowledge as discrete and basic entities - as stable reference points which exist 'out there', beyond social contextuality.
\end{abstract}

Keywords: infrastructures, translation, performance, information technology, ANT 
The development of computer resources for education is often proclaimed to be a catalyst of educational improvement, from teaching materials, to educational processes, information gathering and student activity. The hope is that these digital resources will create a better, more flexible, individualistic, and efficient education. The hypothesis latent in this argument is that technological equipment, software, and infrastructures are seen as panaceas for educational problems, and that access to more information through technology will lead to a better education. Science education is no exception to these ways of thinking about education and computers. Investments in digital educational materials are being made around the world to make science more accessible for students. ${ }^{1}$

This article highlights how an emerging technology for the exchange of digital learning material, so called Learning Objects, although they are understood as being 'pedagogically neutral', are performed along with a particular view of education and knowledge. In this article, I show how the enactment of Learning Objects translates economic and technical considerations - cheaper online education, and cheaper educational material, that is easier to assemble - into a technical object which is linked with an atomistic, non-sequential, and contextless treatment of educational material, knowledge, and pedagogy. In investigating the design of Learning Objects, I show how technology in education is performed at the same time as certain values in the educational setting, which might not be the teachers', administrators', or even engineers' first choice. ${ }^{2}$

By investigating the economic and technological visions that are produced along with Learning Objects, this article highlights an important problem with the techno-enthusiastic perspective in education: its treatment of technology as a neutral tool for expediting teaching objectives and goals - a 'black box' - which hides all the social processes, technological histories, power plays, and beliefs that are put into play around it. Thus the article illustrates how the techno-enthusiastic perspective in education often neglects how the particular arrangements of technical systems for education are performed in conjunction with particular versions of the educational, material, or economic - which could have significant ramifications for educational practice. $^{3}$

I argue that it is crucial to address these issues, since if Learning Objects take root, and spread over multiple educational institutions around the globe, their composition can come to shape the way education is practiced for a long time. At an 
early stage of technological development, values that affect the shape and functionality of technology are put into play - values that might seem neutral to the end goal, but might prove to have unintended consequences. The design and functionality of a computerized educational infrastructure can produce different types of educational landscapes that can either make education better for students and teachers, or become, in the words of Jeffrey Bowker and Susan Leigh Star, 'a franchised, dully standardized infrastructure' (1999, 308).

A crucial question to answer before we tackle these main issues is: - What is a Learning Object? Simply put, a Learning Object can be likened to a digitally 'packaged' building block that wraps educational material of different forms and sizes in a standardized format that can be used to assemble a computerized course. One of the important differences between regular educational material and Learning Objects is that a Learning Object 'package' also includes descriptive data, so called metadata, encoded in a computer readable format that makes it easy to catalogue, index, and, perhaps most importantly, find digital learning material that match certain criteria. The contents of a Learning Object can range from an image, a sound clip, or a diagram to a more complex digital file that encompasses different types of media, interactions, assessments, etc. For example, an image of the Mona Lisa combined with some text, a video, some learning exercises, or a test could constitute the content of a Learning Object. In short, a Learning Object is digital learning material packaged with metadata in accordance with a technical standard.

Learning Objects are growing by leaps and bounds. For example, the company behind the well-known learning management system Blackboard has announced that they will work to make their products compatible with Learning Objects standards. In Europe the eContentPlus programme has funded numerous projects related to Learning Objects. The US Department of Defense has been one of the leading actors in developing Learning Object standards. In Australia and New Zealand, there is a governmental collaborative project called The Le@ @ning Federation, which develops free digital educational material for all Australian and New Zealand schools. In Singapore there is an e-learning portal providing Learning Objects for primary education called LEAD that has 250.000 subscribers. On the other hand, although they garner vast amounts of economic and technical support, Learning Objects are still a technology-in-the-making that has not yet been implemented widely or diffused into a large amount of learning platforms. It remains to be seen if they will gain 
widespread use or have far-reaching effects on education globally (Barlas, 2006). As any technical object that has not yet been fully completed, Learning Objects are still a chimera - a vision in the minds of a group of educational technologists and partly made material through a number of technical standards and objects.

The purpose of this article is to analyze how visions of education and learning are performed in conjunction with the technological object that has been dubbed Learning Objects. The intention of this exercise is to understand the enactment of a material infrastructure and its specific mode of organizing education. The questions that arise from this inquiry are tied to material objects, knowledge, and education: What assumptions about learning are inscribed in Learning Objects? What forms of knowledge do they perform? In the end, the crucial question to ask is what epistemic models become the modus operandi of Learning Objects? What materiality of learning is made beside the emerging standard of Learning Objects? In answering these question I show that the visions of, and standards for, Learning Objects are not a neutrally applicable technology which can be implemented uncritically in education, but that Learning Objects are enacted with certain modes of organizing economy, education, pedagogy and knowledge.

\section{Theoretical Perspective}

In order to analyze the visions performed together with Learning Objects and the inscription of these visions into a technical standard this article draws on the ActorNetwork Theory tradition, which works with the notion of translation. The concept of translation emphasizes the movement of processes, knowledges, and competencies between different entities in a network comprised of both human and non-human actors (Latour, 1999, $174 \mathrm{ff}$.). It attempts to describe how the performance of links translations - between entities transform the whole network at the same time as they modify the member entities (Latour, 2005, 106-108). ${ }^{4}$

In this article, translation is used to emphasize how visions of education, economy, and knowledge are put into play by a group of educational technologists in the production of a technological object, Learning Objects: an idea from one domain of thought is combined with another and this enacts something new. In this case, ideas of economy, object-oriented programming, education, and knowledge are combined, with specific consequences for the performance of Learning Objects and its subsequent inscription in a technical metadata standard. 
A specific sub-concept to translation, inscription, is used to describe how something is translated into more durable form, or how 'an entity is materialized into a sign, an archive, a document, a piece of paper, a trace' (Latour, 1999, 306-307). Inscriptions are closely tied to the work of innovators and engineers:

... when technologists define the characteristics of their objects, they necessarily make hypotheses about the entities that make up the world which the object is to be inserted. Designers thus define actors with specific tastes, competences, motives, aspirations, political prejudices, and the rest, and they assume that morality, technology, science, and economy will evolve in particular ways. A large part of the work of innovators is that of 'inscribing' this vision of (or prediction about) the world in the technical content of the new object. I will call the end product of this work a 'script' or a 'scenario' (Akrich, 1992, 207-208).

The 'script' or 'scenario' that is under scrutiny here is a technical metadata standard for Learning Objects, which, as I will show below, is inscribed with engineering dreams of educational economy, modularization, and knowledge. In essence, this technological script is a performance of a specific materiality of learning. ${ }^{5}$ Inscription - as a form of translation - is used to describe how the vision of Learning Objects is formalized and translated into the formal language of technical compromise of the Learning Object metadata standard. Hence, the article is concerned with the performance of a vision for, and standardization of, Learning Objects as well as the chains of translations that this entails from economy over technology to education and knowledge.

In this article I use the concept epistemic atomism, in an emic manner (Harris 1976), to designate the performance of knowledge as discrete and basic entities ('chunks of knowledge'). I use it to point to the enactment of an ideal Learning Object - a contextless, stand-alone, non-sequential, and granular 'atom of knowledge.' The use of atomism thus points to a specific ordering of Learning Objects, and stems from both the technical standard itself as well as a number of the analyzed texts about Learning Objects. ${ }^{6}$ 


\section{Method \& Material}

Data selection \& Material: Selecting the analyzed data for this article started with five articles from the 2006 International Conference on Distance Education (ICDE) in Rio de Janeiro, which had Learning Objects as their main focus. The ICDE conferences are a series of conferences which are a meeting place for distance educators, distance education companies, as well as governmental bodies from all over the world. The conferences started out small in 1938, while today's conference is a large event involving hundreds of participants, simultaneous translation, visits by ministers of education, as well as large exhibits rented out to educational technology companies.

The original set of five articles from the conference was subsequently expanded through a chain technique, where the reference lists of the original five texts were inspected for articles that contained Learning Objects in the title. This was done in order to identify further texts for qualitative analysis (coding) of intentions, rationales, problems, and solutions connected to Learning Objects (Patton, 1990, 237-238). This method yielded 35 texts in total that were relevant to understand the vision of Learning Objects. In all, the 35 texts amounted to approximately 500 pages of material. The selected texts were chiefly written by educational technology engineers, educational technology researchers and educational visionaries that have been involved in developing, implementing, or using Learning Objects.

In addition to these texts, the IEEE standard on metadata for Learning Objects (IEEE LOM, see IEEE, 2002) was analyzed in order to investigate how the vision of Learning Objects was formalized in a technical standard. The analyzed standard is a technical description of the characteristics, properties, formats, and definitions that pertain to the metadata 'packaged' with a learning object. The heart of the IEEE LOM standard document is a table of named metadata properties, for example 'aggregation level', with descriptions as to what they describe and how they can be formatted. ${ }^{7}$

To understand what a metadata standard is, think about a library record for a book, this record is metadata about the book. A standard for metadata specifies which fields should be present in the metadata record and how they should be formatted. For example an ISBN number is formatted in a certain way (13 digits in order to be compatible with bar-codes), or the type of material might be chosen from a precompiled list of available types (book, journal, audiovisual, dissertation). The 
metadata standard for Learning Objects specifies a number of properties that a Learning Object can be described with, and thus shows what parts of the vision are deemed important enough to standardize and diffuse globally. Thus, the standard is not only a technical document but a document which enacts a technical object with an educational future.

Method: The qualitative coding of the 35 texts was executed through an oscillation between two different analytical techniques with a focus on understanding the vision of Learning Objects. The first technique was to study the texts for passages that performed the intentions, rationales, problems, and solutions connected to Learning Objects. In this, my focus lay on understanding the hypothesis about education and knowledge that was tied to Learning Objects, rather than utterances that considered technical subtleties of implementation (like server design, or XML details), theoretical discussions of Learning Objects (like how they could be understood using Pierces theory of signs), or matters of tangential importance for the general vision (like the semantic web). The second technique involved the generation of codes and categories that classified and grouped the relevant passages. Many concepts, and groups of concepts were generated from this process, like standardization, classification, flexibility, efficiency, personalization, or interoperability. The most important categories for the understanding of the intentions, rationales, problems, and solutions connected to Learning Objects were reusability, interoperability, or economies of scale, as will be discussed throughout the article. ${ }^{8}$

Finally, to elucidate how different aspects of Learning Objects were performed - translated - I followed how the actors linked key aspects of their vision, i.e. how the primary reason for implementing Learning Objects was expressed as being reusability and economy, and how this vision was linked to a particular way of achieving it. Furthermore, to analyze how this vision of the world was translated into more durable form and inscribed in the technical content of Learning Objects I scrutinized the IEEE LOM standard in order to identify how, and if, the vision of Learning Objects found its way into a technical standard. This process entailed reading and understanding the technical specifications of the standard in light of the results from the qualitative analysis. Through this move, I could for example discern the link made between a technical metadata property in the IEEE LOM called 'granularity' and an educational vision for modularization and granularity in the qualitative material. 
Through the combination of materials it became possible to analyze both the performance of Learning Objects, as well as a specific vision of education. In the article, I have chosen a number of illustrative quotes in order to demonstrate how these visions were expressed, and for elucidating the enactment of epistemic atomism in the material.

\section{What's the Problem? Cost Efficiency and Reusability}

The first step in understanding the composition of Learning Objects as objects is to understand the intentions that are expressed in relation to them. Thus, we start in the 'vision of the world' that the proponents of learning objects express. This section outlines the purposes that are attached to Learning Objects. What are they expected to do? What are the problems to be solved? What are the rationales to develop Learning Objects? This is the first step in understanding how a technical object can translate a set of economic intentions into another set of intentions that pertain to pedagogy and education - and in so doing perform a specific materiality of learning.

The vision of Learning Objects enacts a close connection to economy. In the studied material, the primary reason for developing Learning Objects is to share the high development costs for digital educational material among a larger number of institutions and users (Downes, 2004b). As Stephen Downes, a specialist on online learning from the National Research Council of Canada, expresses it:

We can lower the cost of learning. Imagine a multimedia company spending a million dollars on such a [multimedia Hamlet] production. Assume that Hamlet is taught in 10,000 schools, colleges or universities around the world (hardly a stretch). Assume 20 students per class (an underestimate, to be sure!). At $\$ 5$ per student, the company would make its million dollars back in one year! The economics are very good, and this excellent resource would be cheaper than even the book alone. (Downes, 2004b, 24)

Consequently, the intentions that are performed alongside Learning Objects include a vision of economies of scale in which educational content is seen as a commodity that can be reused in different educational 'market sectors, localities, cultures, or educational levels' through their possibility for reuse and adaptation (Weller, 2004). Rory McGreal, who is the Associate VP of Research at Athabasca University - 
Canada's Open University - and in charge of implementing the IEEE's Learning Object Model in Canada, expresses the idea like this: ' $[\ldots]$ the world does not need tens of thousands of similar learning topics. [...] a dozen well designed multimedia [Learning Objects] could be used in thousands of courses' (McGreal, 2004, 3). According to him (this time with Griff Richards, Marek Hatala, who are distance education technologists with a long standing interest in technology and education) the perceived key to achieving economies of scale is to design Learning Objects so they are reusable:

The promise of digital LOs [Learning Objects] lies in reusability. If constructed appropriately, warehoused wisely and catalogued accurately, then a LO might find usage beyond its original audience and instructional context. Given the relatively high cost of developing good LOs, the promise of reusability receives considerable attention from administrators and publishers trying to amortize the cost of production and maximize the potential return for each of these digital investments. (Richards, Hatala \& McGreal, 2004, 236)

For the proponents of Learning Objects, the purpose of the information infrastructure is the exchange of materials and student profiles in a digital marketplace for educational material. As Wayne Hodgins, the former chairman for the IEEE Learning Technology Standards Committee on metadata and a pivotal actor in the Learning Objects field puts it:

Just as we have created grocery stores to provide us with the raw materials (and sometimes more) for our meals, and these stores are carefully geared to meet the predictable demands of their customers, so in the future we will receive Learning Objects as our needs arise, based on the predictability of those needs as determined from past behavior. The dramatic efficiencies of automation, such as bar codes and scanners that have assumed the functions of price tags and cash registers, will be mirrored in the learning arena by metadata standards, collaborative filtering of information, etc., all of which require standardization just as grocery stores require standard labeling and coding of the products they sell. (Hodgins, 2000, 7) 
Hodgins' vision, is not only a dream of a visionary, but begins to compose a specific object through the development of a technical standard for Learning Objects. As I have outlined above, the dominating intention behind the development of Learning Objects is economy and reusability, and thus, these concerns are constitutive of the development of Learning Objects standards. But how do these values, dreams of the future, become enacted in a technical standard? And how are they translated into the educational domain?

\section{Translation I: Economy and Reusability}

The first step, inscribing the idea of economies of scale into the technical domain, happens in the first accepted IEEE standard for educational technology. This standard was published in June 2002, and was called the 1484.12.1 Learning Object Metadata standard (IEEE LOM). The IEEE LOM aimed to produce a standard for classifying and cataloging Learning Objects (IEEE, 2002), and defines a basic framework for classifying Learning Objects. It specifies a number of important attributes that are to be used to assemble new courses, in the search for suitable Learning Objects, or in the cataloging of Learning Objects in large databases. The IEEE LOM also enacts a specific vision of education - albeit in a technical form.

The stated intentions behind the development of the metadata standard is to make it possible to search, evaluate and acquire Learning Objects (IEEE, 2002, 1). The IEEE LOM framework defines vital information about where to find the Learning Object: who authored it, what version it is, what language it is authored in, to what subject does it pertain, etc. Consequently, the IEEE LOM standard specifies how educational content should be classified and described so that computer systems and humans can 'manage, locate, evaluate, or exchange Learning Objects' (IEEE, 2002, 1). Norm Friesen, the Canada Research Chair in E-Learning Practices at Thompson Rivers University, Susan Hesemeier, working on the Canadian standardization project CanCore, and Anthony Roberts, from the Telecampus repository for TeleEducation in Canada, argue:

Careful and coordinated implementation of the LOM standard is the linchpin of many of the visions of discoverable, accessible and reusable educational objects. (Friesen, Hesemeier \& Roberts, 2004, 235) 
Accordingly, the accomplishment of reusable Learning Objects is seen as being dependent on propagating a technical standard, the IEEE LOM, that allows economies of scale through the reuse of digital educational resources between different technical systems. This is the first link in the chain of translation. Through performing a link between economies of scale and a specific organization of educational material the proponents of Learning Objects are translating economies of scale $\rightarrow$ reusability. How ideas of reusability and economies of scale are translated into a standard for metadata, and the chain of translations that leads from economy to epistemic matters are the concerns of the remainder of this analysis. Here, the question of how technoeconomic concerns become epistemic atomism is in focus. How does a technical standard come to perform a specific mode of organizing knowledge and educational material?

\section{Translation II: Achieving Reusability through Modularization}

In the Learning Objects field, many of the proponents of Learning Objects argue that the maximum reusability of educational material will be achieved through splitting educational material up into modules. Pertaining to Learning Objects, modularization means that each course is metaphorically seen as being constructed of a multitude of parts, or digital media components, that are combined to form a whole course. The purpose is to construct an online course that is comprised of several Learning Objects. The course constructor only needs to select a number of Learning Objects and assemble them into a series that the student can use to learn. The argument is that large chunks of material are seen as unsuitable for reuse and remixing into new courses, as they are not flexible enough. Therefore it is seen as desirable to divide the courses into parts taking the form of Learning Objects:

Courses themselves are not suitable candidates for sharing. ... So, we will share parts of courses. What needs to be shared may be best described as parts of courses, or more accurately, course components. (Downes, 2004b, 26)

In this vision, a high degree of modularization is claimed to enhance the ability to reuse a Learning Object. As Mohamed Ally, the Director of the Centre for distance Education at Athabasca University in Canada, expresses it: 'Programmes and courses of instruction need to be designed into smaller units in the form of LOs to make them 
flexible and reusable' (Ally, 2004, 94). The idea of modularization of educational material draws heavily on computer science and object oriented programming, which has developed a number of strategies for dealing with reusability. Stephen Downes discusses the relation between object oriented programming and Learning Objects as follows:

An online course, viewed as a piece of software, may be seen as a collection of reusable subroutines and applications. An online course, viewed as a collection of LOs, may be seen as a collection of reusable learning materials. The heart and essence - of online course design is the merging of these concepts, of viewing reusable learning materials as reusable subroutines, applications and documents assembled by application specialists in a computer-assisted software environment. (Downes, 2004a, 99)

So, the chain of translations I am following now starts with economies of scale and reusability which are subsequently translated into an idea of modularization, which stems from object orientated architecture in computer science. Here two ideas from previously unconnected domains are combined by the Learning Object designers and translate a shift in the enactment of Learning Objects. Through the idea and practice of object oriented programming, the Learning Objects becomes slightly differently performed. From being an economic matter of reusability into a technological solution built on modularization. As I will show below, the performance of the modular Learning Object puts into play a specific mode of organizing, which links the technical domain with the epistemic - epistemic atomism.

According to the texts, the most important reason for technical modularization is the possibility to use each Learning Object as a building block for constructing a new course. Accordingly, educational concerns with course-development costs are, through the idea of modularization in object-oriented programming, translated into a specific technical solution - modularization. The chain of translation has become economies of scale $\rightarrow$ reusability $\rightarrow$ modularization. The performance of Learning Objects have shifted domain from economy and reusability, to the technical. In order to understand what modularization entails, our questions now become: What is to be modularized? How is modularization to be achieved? Which properties of Learning 
Objects are to be subdivided into 'atomic' granules - as they are called in the IEEE LOM?

\section{Translation III: The Ideal Size of a Learning Object}

In the texts on Learning Objects there is a consensus that Learning Objects should be smaller than a course so that they can be used as building blocks for new courses. However, there is also agreement that the Learning Object cannot be so small so as to encumber development or become unmanageable. The most economically beneficial size is still an uncertain matter for the proponents of Learning Objects. The 'size' of a Learning Object can range from a raw media object, e.g., a digitalized image, a sound clip, or a diagram, to a set of complete courses consisting of raw media, interactions, assessments, etc. The size of the Learning Object is often referred to as 'granularity', or 'granule size'. Here the technical moves ever-closer to the epistemic and educational. Technology is performed with the epistemic.

This vision of granularity is deemed so important for the standardized Learning Object so that it is inscribed in the IEEE LOM through the definition of a specific metadata property that divides Learning Objects into different levels of granularity. This property is called aggregation level. In the aggregation level property, ideas about economy and modularization are inscribed in the IEEE LOM. The aggregation level property classifies the 'functional granularity' of the Learning Object: the first level of granularity equals 'raw media or fragments;' the second, a lesson; the third, a course; the fourth, 'a set of courses that lead to a certificate.' So, although the vision of Learning Objects expresses an aspiration for small granules, this is not mirrored entirely in the IEEE LOM standard, a fact that reflects an uncertainty as to the most practical size of a Learning Object.

However, the argument is that size is a crucial matter for reusability. With a large granule size (imagine a granule the size of a course) the possibility of flexibly reassembling courses diminishes greatly. With a medium granule size (imagine a granule the size of a chapter or an article) there is quite some leeway in reassembling the granules into courses while still retaining a quite flexible way of reconstructing courses. With a small granule size (imagine a granule the size of a picture, a formula, or a video) the flexibility of repurposing becomes very high, but also the level of work needed to produce a coherent course rises. Thereby, not all levels of granularity 
defined in the IEEE LOM aggregation level property perform the same vision of reusability and economies of scale.

So, although there is flexibility inscribed into the IEEE LOM aggregation level property, the vision of a reusable and granular information infrastructure for education is tied to a certain performance of Learning Objects. In accordance with the economic vision of reusability it is argued that the Learning Objects need to be so small that the size facilitates flexible repurposing of content: Erik Duval, who is a professor at the research unit on hypermedia and databases from the Catholic University of Leuven, and Wayne Hodgins put the question of granularity as follows:

Many actors in this research domain limit their vision of LOs to that of traditional documents or software applications (e.g. simulations). However, the current state of technology allows us to consider a much smaller level of granularity that enables more flexible and effective repurposing of content.

(Duval \& Hodgins, 2004, 73)

Thus, in the vision of Learning Objects it is argued that the size is supposed to be of the smallest grain practically possible in order to facilitate maximum flexibility. This is to pave the road for the reuse and repurposing of the objects into new combinations that can be used in different courses and settings.

There are further translations at work here, which move the concern for economy through reusability toward the epistemic domain. Rather than basing a module on what is practical from an epistemic point of view, the argument is that the basis for subdividing the Learning Objects should be to lower the grain size in order to facilitate reusability. Hence, the economic intentions are translated into technical modularization via object-oriented programming. The chain of translation becomes economies of scale $\rightarrow$ reusability $\rightarrow$ modularization $\rightarrow$ granularity. Each move along the chain shifting matters subtly: from economy to technology, and from technology to epistemic matters.

\section{Translation IV: Self-Contained, Non-Sequential, and Contextless Learning Objects}

With the quest for economies of scale and reusability, and in line with the technical emphasis on modularization, the proponents of Learning Objects argue that the ideal 
modular Learning Object has three crucial characteristics associated with it: selfcontainment, non-sequentiality, and independence from an external context. The argument is that these three characteristics are essential in order for a Learning Object to become increasingly modular and accordingly reusable, thus facilitating economies of scale. The ideal Learning Object is seen as treating information as 'atoms' of knowledge. Here technical modularization increasingly moves toward a performance of epistemic atomism.

The first characteristic of the Learning Object, self-containment, emphasizes that the Learning Object should not be dependent on references to other components. In the vision for Learning Objects it is argued that they must only refer to resources that can be found within themselves: for example, Mohamed Ally argues that 'One should be able to revise LOs without affecting other objects... This requires that the LOs be independent and stand-alone' (Ally, 2004, 88). Consequently, it is argued that all information, exercises, assessments, and services utilized in the Learning Object must be contained within the Learning Object. Duval and Hodgins also agree on this point and argue that:

Authors should avoid explicit references to other components, as these other components may not be available in the context of reuse. ... a reference to 'chapter V' makes little sense if the context in which a component is reused doesn't include a 'chapter V'.... This is one example of an issue that needs to be considered when content is designed to be reusable. (Duval \& Hodgins, 2004, 78)

The self-containedness of the Learning Objects aims to allow the addition or subtraction of a Learning Object to or from a course, without affecting the course as a whole. The argument is that the breaking down of educational material into its fundamental parts will allow the reuse, remixing, and restructuring of Learning Objects. As a consequence, removing connections between different chunks of educational material and creating contextless units of learning material is extolled as being an ideal state for creating reusability.

The second characteristic of the atomic Learning Object that facilitates reusability through modularity is non-sequentiality. Monique Doorten (et al.), from 
the Open University of the Netherlands, argues that in order to maximize reusability resources cannot depend on prior or subsequent Learning Objects:

In order to ... [determine the smallest intrinsically meaningful parts] we need to check whether the distinguished objects meet the requirements of being reusable in the sense that they appear to be self-contained and ideally non-sequential ... meaning that all concepts, principles, methods and so on are sufficiently explained within the object itself. ... Non-sequential therefore means that objects should be without any references to any presumed prerequisite prior knowledge, other than through the use of metadata. (Doorten et al., 2004, 125)

In the quote above, the translation from the economic vision of reusability into the epistemic domain becomes clear. It is not only a technoeconomic matter to modularize, but it also affects epistemic matters deeply. Hence, technoeconomically motivated modularization becomes translated into a modularization of knowledge, epistemic atomism.

This non-sequentiality of the atomic Learning Object is also inscribed into the IEEE LOM through a metadata property designated structure. In this metadata property the concept atomic is used explicitly to refer to the most granular Learning Objects. This property defines a classification of Learning Objects into atomic, collection, networked, hierarchical, or linear. An atomic Learning Object is defined as 'an object that is indivisible' and as 'raw media or fragments;' a collection as a 'a set of objects with no specified relationship between them;' a networked Learning Object as a 'a set of objects with relationships that are unspecified;' hierarchical as a 'a set of objects whose relationships can be represented by a tree structure;' and linear as a 'a set of objects that are connected by 'previous' and 'next' relationships.' The structure property of the IEEE LOM is inscribed with a number of different ways of organizing Learning Objects, and translates specific epistemic relations and ways of learning into a technical standard. As a result, the IEEE LOM is inscribed with a number of characteristics with different degrees of compatibility with a vision of economies of scale through reusability, but also with different ways of traversing the Learning Objects, and working in the system.

The third characteristic of the modularized Learning Object is how context is understood. For the proponents of Learning Objects, educational and informational 
context in light of the wish for modularization becomes a problematic issue that needs to be addressed in order for the maximum reusability to be achieved. Robby Robson, Vice Chair of the IEEE Learning Technology Standards Committee and Vice President of the Eduworks Corporation, maintains:

Context also affects reusability. Dependence on context diminishes opportunities for reuse, which acts as a disincentive to produce reusable objects in the first place. The degree of this diminution is a function of both the depth of dependence on context and the narrowness of the context.... A LO that makes sense only in a narrow context has less potential market size. (Robson, 2004, 160)

Robson argues that the solution to the problem of epistemic context and economic reusability in Learning Objects is the implementation of technical metadata standards. Through providing an epistemic context in the Learning Object, like language, subject, student age, or educational level he argues that the reassembly Learning Objects will be less complex. His argument is that through implementing standardized metadata, the context of the Learning Object can be inscribed in the information infrastructure and thereby create preconditions for reusability. Through creating a technological framework for reusability, economy can be achieved:

... LOs may not be as reusable as one would hope for. Context has been identified as being the culprit. The highly contextual nature of LOs adds significant cost to reuse. [but] standards ... have the effect of preserving the context of a $\mathrm{LO}$ as it is handed off from person to person and system to system. ... This makes reuse even more attractive and at the same time increases the inherent value of LOs. With standards in place, along with appropriate practice built around the standards, predictions of educational object economies ... may well end up being correct. (Robson, 2004, 166)

Through inscribing a context consisting of language, intended audience, subject matter, cultural context etc. in the Learning Object metadata, the 'context' is to be preserved in the Learning Object package. In this way, context is to be made available in every Learning Object through the inscription of metadata into its standardized 
package. The epistemic context of a Learning Object is translated into standardized technological and epistemic metadata in order to achieve economies of scale.

What I have shown above is how technical and economic concerns are translated into the domain of knowledge, information, and pedagogy. What is an economically and technically motivated idea, modularization, becomes translated into a matter of handling epistemic matters. What at the outset was a problem of economy has become an epistemic and pedagogic solution. The chain of translation has become economies of scale $\rightarrow$ reusability $\rightarrow$ modularization $\rightarrow$ granularity $\rightarrow$ the epistemic. The technoeconomic has become the epistemic and pedagogical. As I have shown above, the IEEE LOM standard performs a classification of Learning Objects that allows a degree of flexibility in how modular or granular a Learning Object can be, but there is also an attached hierarchy of desirability between these different classes of objects, where the modularized, non-sequential, contextless - the atomic Learning Object - is the most desirable. Through these idealized characteristics, in both the IEEE LOM and the utterances about Learning Objects, epistemic atomism - an atomistic materiality of learning - is performed.

\section{The new atomic and molecular science of education and the chimera of universality}

Taken together, the stand-alone character and non-sequentiality of Learning Objects means that courses are to be materialized and broken down into building blocks that allow for the construction of new courses, and new content. Through freeing the Learning Objects from their context and from their sequentiality, universal reusability is to be achieved. Reusability has been translated into an atomic, contextless, epistemic/pedagogical project. Wayne Hodgins expresses the extreme vision of a modularized educational information infrastructure as the new atomic and molecular science of education:

I believe we are on the verge of a grand discovery in the areas of learning, content, knowledge, and objects. Just as revolutionary as our discovery of the atomic and molecular models will be our discovery of the equivalent of the periodic table for all content or data. [...] Similarly, an equivalent understanding of our data and informational world will give us a fundamental understanding and ability to manipulate, create, and build any substance 
possible. In the case of data, this model will be based on the ability to take everything down to fundamental units, understanding their basic structural makeup and components, the equivalents of their electrons, neutrons, protons that combine to form compounds. (Hodgins, 2000, 12)

Hodgins vision is telling for how knowledge is understood in relation to the standardized Learning Object. What was once a matter of economy, and subsequently was translated into technology, has now clearly become a matter of information, knowledge, or pedagogy. Information and knowledge that are to be granularized and understood in their structural make-up so that 'the 'rules' that govern what can be combined and how' can be discovered (Hodgins, 2000).

This begs the question of what pedagogies and knowledges Learning Objects are compatible with? In line with the arguments made by Sørensen (2009), Learning Objects can be seen as performing a representational knowledge-space, where knowledge is defined as stable reference points 'out there' which are transferred between knowing subjects, in contrast to, for instance, participant learning that is performed through performances and apprenticeship (Sfard, 1998).

Accordingly, Learning Objects and their metadata standard can be seen as performing a specific metaphor for knowledge that is quite strongly geared toward the acquisition of knowledge, rather than situated learning practices (Guribye, 2005, 172 ff.). The question is what type of pedagogy one would like the Learning Object infrastructure to be compatible with? It is quite clear from the vision of Learning Objects that this pedagogy is not neutral, but that it stages a specific configuration of learning, thus excluding others. Being uncritically enthusiastic to ICT in schools becomes a problematic exercise when bearing this in mind: every infrastructure for education is performed with a specific educational vision, with certain technological components. And they are not neutral.

Could it be otherwise? Could the vision for Learning Objects and the IEEE LOM standard be reconfigured to reflect a fundamentally different logic than economies of scale and epistemic atomism? As Hamilton and Feenberg have argued it is quite possible to produce computerized learning platforms for collaboration, dialogue, and social learning, but such platforms are expensive to operate as they require large amounts of manpower (Hamilton \& Feenberg, 2005, 112). Thereby, the economies of scale could be lost, but a social, contextual, and participant way of 
handling knowledge could be won. In essence Learning Objects solve the initial problem they were set out to solve: economy. But to argue that they are pedagogically neutral would be deceptive, as they perform an epistemic atomistic, and a specific materiality of learning.

The questions above are questions of infrastructural politics that are crucial to reflect upon in order to imagine a desirable educational future - a desirable infrastructure of learning. However, here I will stop following this chain of translations. Economies of scale have become translated into modular, contextless, one-size-fits-all Learning Objects. What started out as a dream of splitting production costs between a greater number of institutions, has been translated into a specific way of handling information, knowledge, and pedagogy. A technical standard aimed at lowering production costs performs an atomistic materiality of learning - epistemic atomism. In the vision of Learning Objects the economic, became the technical, and the technical became the epistemic.

\section{Conclusion}

I started this article with asking which particular views of education and knowledge were inscribed in the design of an emerging standard for the exchange of digital learning material. Initially I analyzed the guiding visions of the technological development. I showed how proponents of Learning Objects argued that digital learning material was expensive to produce; the solution to this problem was the reuse of Learning Objects in different courses and settings so that economies of scale could be achieved. Furthermore, I showed how the problem of cost efficiency and the solution of reusability was translated into a technological solution: here Learning Object were performed as ideally being modular, so as to be possible to reassemble and reuse. To achieve this it was argued that they needed to follow a specific standard - the IEEE LOM standard. Third, the IEEE LOM performed the ideal Learning Objects as being 'granular', i.e. small, self-contained, non-sequential, and contextless, so that they could be reused without needing to be repurposed.

For understanding the specific materiality of learning, which LOs puts into play, I applied the concept of 'translation' from ANT. The concept of translation focuses on the movement of knowledges, processes, and competencies between different entities in human and non-human networks. The shifts between the intentions for Learning Objects and how knowledge is performed are examples of translations between the 
economic and the epistemic: a vision of economies of scale is translated into reusability, reusability into modularization, and modularization into the atomic, universal, self-contained, and non-sequential Learning Object. The chain of translations becomes: economies of scale $\rightarrow$ reusability $\rightarrow$ modularization $\rightarrow$ granularity $\rightarrow$ epistemic atomism. Economy and technology were performed along with pedagogical/educational design. In the parlance of translation and inscription, what I have shown is how a specific script or scenario for education was created through a chain of translations in and around the IEEE LOM. This script, which put into play a specific materiality of learning, included many different fictions, technological solutions, and visions about education, and is by no means yet stabilized - it is still in the making.

The technological script that the proponents of Learning Objects have created in the form of a technical vision and standard - performs what I have called epistemic atomism: which includes the enactment of modularity, universality, and nonsequentiality. By choosing to solve the problematization of economies of scale and reusability with modularized and contextless Learning Objects, the proponents have put together the script in a certain way. An important point to make about this performance of education and knowledge is that epistemic atomism is not necessarily a mode of ordering which is supported by the human proponents of Learning Objects. Rather, my argument is that it is a result of assembling an array of things that shape how Learning Objects are organized: human visions, economic rationalities, technical solutions, problem solving methods from computer science, etc. Hence, the proponents of Learning Objects would probably not explicitly argue for an atomistic and contextless educational experience if pressed. Intended or unintended, Learning Objects thus perform a specific mode of organizing learning and knowledge - they perform a materiality of learning geared towards epistemic atomism.

The vision of Learning Objects might seem an educational utopia to many, and it might hold great promise for harnessing technical developments for educational purposes - but arguably there could be a backside to such technical developments as well. The risk is that a large-scale implementation of an information infrastructure built on standardized Learning Objects will be strongly geared toward intensifying already strong tendencies toward educational atomization in the global educational landscape. If the IEEE LOM standard becomes widely diffused and implemented this 
might create a landscape where atomization of knowledge in the form of Learning Objects is the default modus operandi. Is this what we desire?

\section{Acknowledgements}

I would like to acknowledge my editors Estrid Sørensen and Gertraud Koch for their essential work in making this article what it is. The intellectual milieu of the Department of Thematic Studies and especially my discussions with Vasilis Galis, Per Gyberg and Jenny Lee have been crucial for this article, as well as those with Ulf Mellström, Boel Berner, Jonas Anshelm, Katherine Harrison, Martin Hultman, Karin Skill, and Sven Widmalm.

${ }^{1}$ See for example the many projects in the eContentPlus programme of the European Union, http://ec.europa.eu/information_society/activities/econtentplus/projects/funded_projec ts/index_en.htm The techno enthusiastic perspective in education has been criticised by several scholars, notably David Noble, Digital diploma mills: the automation of higher education (New York: Monthly Review Press, 2002), Douglas D. Noble, The classroom arsenal: military research, information technology, and public education (London: Falmer Press, 1991), Cuban, L. (2001) Oversold and Underused: Computers in the classroom (Cambridge, MA: Harvard UP).

${ }^{2}$ A central point of departure for this article is the longtime engagement with classification, standardization, and infrastructures within STS, which treat standards and infrastructures as deeply political (Barry, 2001; Bowker \& Star, 1999; Hanseth, Monteiro \& Hatling, 1996; Star, 1991; Star \& Ruhleder, 1996). In this line of inquiry, infrastructures and standards are seen as political in several ways. For example they contain complex encoded histories, which are folded into both the inscribed data and into its classificatory mechanisms and often forgotten. Also, that which is not deemed as being of 'economic, aesthetic, or philosophic importance' is often excluded from the information infrastructure and rendered invisible (Bowker, 2000, 659). Thus, infrastructures and standards operate normatively to favor certain narratives and understandings of encoded data (Bowker, 1998, 2000). An important point is that infrastructures tend to become increasingly obdurate and irreversible as they are diffused. Thus infrastructures and standards hold the power to distribute ideas and practices in both time and space (Callon, 1991).

${ }^{3}$ See Lee, Francis. 2009. Letters \& Bytes: Sociotechnical Studies of Distance Education. Linköping: LiU Press for a more thorough discussion of determinism in education.

${ }^{4}$ The concept of translation stems from the French philosopher Michel Serres, who used it to denote 'an act of invention brought about through combining and mixing varied elements' (Brown, 2002, 6). Accordingly, a translation is a 'displacement, drift, invention, mediation, the creation of a link that did not exist before and that to some degree modifies the original two' (Latour, 1999, 179). The 
processes of translation always run the risk of betraying, or changing, the direction of the network in unforeseen ways, and accordingly the translation is not always a straightforward matter (Callon, 1986; Law, 1997).

${ }^{5}$ There is an important caveat that must be made in relation this point: the users of Learning Objects are still to interpret and subscribe to the script, which might be significantly changed in practice. Nevertheless, the script that is inscribed in the IEEE LOM standard will be an actor in determining how online learning will be practiced, and as such is important to understand in its own right.

${ }^{6}$ I use of the prefix epistemic, to refer to the production of a part of a 'machinery of knowledge production', rather than 'the production of knowledge' (Knorr Cetina 1999, 11). I.e. rather than investigating the production of knowledge in a school setting, like Sørensen or Benjaminsen (in this issue), I study the production of an educational machinery of knowledge production.

${ }^{7}$ Important standardization organizations involved in the development of standards for an educational infrastructure are the IEEE Learning Technology Standards Committee (IEEE LTSC); the European Committee for Standardization, Learning Technologies Workshop; the ISO/IEC Standards for Learning, Education and Training; the Dublin Core Metadata Initiative (DCMI); as well as the IMS Global Consortium (IEEE, 2005). The standard that is analyzed here is the IEEE 1484.12.1 2002 Standard for Learning Object Metadata, or IEEE LOM for short (IEEE, 2002). In this article I analyze the IEEE LOM standard as it was the first accepted metadata standard for educational purposes (Nilsson et al., 2008), and as such is indicative of the goals and ways of thinking in the early efforts for creating Learning Objects. Various earlier projects that tried to define a metadata standard for education were incorporated into the IEEE LOM: the European Union financed ARIADNE projects, the IMS industrial consortium project, as well as the work by the Dublin Core group, an early implementation of learning material metadata, were all integrated into the work with the IEEE metadata standard (IEEE, 2002, iii).

${ }^{8}$ These techniques were inspired by the coding techniques outlined in grounded theory, but do not constitute a full-fledged grounded theory approach. (Strauss \& Corbin, 1990)

\section{References}

Akrich, M. (1992) The De-Scription of Technical Objects, in W. E. Bijker \& J. Law (eds.) Shaping Technology Building Society: Studies in Sociotechnical Change, pp. 205-224 (Cambridge, MA: MIT Press).

Ally, M. (2004) Designing effective learning objects, in R. McGreal (ed.) Online Education Using Learning Objects (London: Routledge).

Barlas, C. (2006) Digital Rights Expression Languages (DRELs) (London: Joint Information Systems Committee).

Barry, A. (2001) Political Machines (London: Athlone).

Bowker, G. C. (1998) The Kindness of Strangers: Kinds and Politics in Classification Systems [Electronic Version], Library Trends, 47(2) pp. 255-293.

Bowker, G. C. (2000) Biodiversity Datadiversity, Social Studies of Science, 30(5) pp. 643-683.

Bowker, G. C. \& Star, S. L. (1999) Sorting Things Out: Classification and its consequences (Cambridge, MA: MIT Press). 
Brown, S. D. (2002) Michel Serres: Science, Translation and the Logic of the Parasite, Theory Culture Society, 19(3) pp. 1-27.

Callon, M. (1986) Some elements of a sociology of translation: domestication of the scallops and the fishermen of St Brieuc Bay, in J. Law (ed.) Power, Action and Belief: A New Sociology of Knowledge, pp. 67-83 (London: Routledge).

Callon, M. (1991) Techno-economic networks and irreversibility, in J. Law (ed.) A Sociology of Monsters: Essays on Power, Technology and Domination, pp. 132165 (London: Routledge).

Doorten, M., Giesbers, B., Janssen, J., Daniels, J. \& Koper, R. (2004) Transforming existing content into reusable learning objects, in R. McGreal (ed.) Online Education Using Learning Objects, pp. 116-127 (London: Routledge).

Downes, S. (2004a) Learning objects: construction and creation, in R. McGreal (ed.) Online Education Using Learning Objects, pp. 98-103 (London: Routledge).

Downes, S. (2004b) Learning Objects: Resources for Learning Worldwide, in R. McGreal (ed.) Online Education Using Learning Objects, pp. 21-31 (London: Routledge).

Duval, E. \& Hodgins, W. (2004) Learning Objects Revisited, in R. McGreal (ed.) Online Education Using Learning Objects, pp. 71-81 (London: Routledge).

Friesen, N., Hesemeier, S. \& Roberts, A. (2004) CanCore: Guidelines for learning object metadata, in R. McGreal (ed.) Online Education Using Learning Objects, pp. 225-235 (London: Routledge).

Guribye, F. (2005) Infrastructures for Learning: Ethnographic Inquiries Into The Social and Technical Conditions of Education and Training, Ph. D. thesis, (Bergen, NO: University of Bergen).

Hamilton, E. \& Feenberg, A. (2005) The Technical Codes of Online Education, ELearning, 2(2) pp. 104-121.

Hanseth, O., Monteiro, E. \& Hatling, M. (1996) Developing Information Infrastructure: The Tension Between Standardization and Flexibility, Science, Technology, \& Human Values, 21(4) pp. 407-426.

Harris, M. 1976. History and significance of the emic/etic distinction. Annual Review of Anthropology 5:329-350.

Hodgins, W. H. (2000) The future of learning objects, viewed 25 April 2008, http://reusability.org/read/chapters/hodgins.doc.

IEEE. (2002) IEEE Standard for Learning Object Metadata (New York: IEEE).

IEEE. (2005) Collaborating Organizations, viewed January 7 2009, http://www.ieeeltsc.org/about/collaborating_organizations.

Knorr Cetina, Karin D. 1999. Epistemic cultures: how the sciences make knowledge. Cambridge, Mass.: Harvard University Press.

Latour, B. (1999) Pandora's Hope: Essays on the reality of science studies (Cambridge, MA: Harvard UP).

Latour, B. (2005) Reassembling the social: an introduction to actor-network-theory (Oxford: Oxford UP).

Law, J. (1997) Traduction-Trahison: Notes on ANT, viewed May 2 2005, www.lancs.ac.uk/fss/sociology/papers/law-notes-on-ant.pdf.

Lee, F. (2009) Letters \& Bytes: Sociotechnical Studies of Distance Education (Linköping: LiU Press).

Major Programme V: Communication and information. (2005) (Paris: UNESCO). 
McGreal, R. (2004) Introduction, in R. McGreal (ed.) Online Education Using Learning Objects, pp. 1-16 (London: Routledge).

Nilsson, M., Naeve, A., Duval, E., Johnston, P. \& Massart, D. (2008) Harmonization of Metadata Standards (Prolearn: Network of Excellence in Professional Learning).

Noble, D. (2002) Digital Diploma Mills: The Automation of Higher Education (New York: Monthly Review Press).

Noble, D. D. (1991) The classroom arsenal: military research, information technology, and public education (London: The Falmer Press).

Patton, M. Q. (1990) Qualitative Research and Evaluation Methods, 3 edn (London: Sage).

Richards, G., Hatala, M. \& McGreal, R. (2004) POOL, POND and SPLASH: Portals for online objects for learning, in R. McGreal (ed.) Online Education Using Learning Objects, pp. 236-243 (London: Routledge).

Robson, R. (2004) Context and the role of standards in increasing the value of learning objects, in R. McGreal (ed.) Online Education Using Learning Objects, pp. 159-167 (London: Routledge).

Sfard, A. (1998) On Two Metaphors of Learning and the Dangers of Choosing Just One, Educational Researcher, 27(2) pp. 4-13.

Sørensen, E. 2009, 'The Materiality of Learning: technology, knowledge and presence in educational practice'.

Star, S. L. (1991) Power, Technologies and the Phenomenology of Conventions: on being allergic to onions, in J. Law (ed.) A sociology of Monsters: Essays on Power, Technology and Domination, pp. 26-56 (London: Routledge).

Star, S. L. \& Ruhleder, K. (1996) Steps Toward an Ecology of Infrastructure: Design and Access for Large Information Spaces, Information Systems Research, 7(1) pp. 111-134.

Strauss, A. \& Corbin, J. (1990) Basics of Qualitative Research: Grounded Theory Procedures and Techniques (London: Sage).

Weller, M. (2004) Learning objects and the e-learning cost dilemma Open Learning, 19(3) pp. 293-302.

\section{Biographical note}

Francis Lee is an Assistant Professor at the Department of Thematic Studies -

Technology and Social Change at Linköping University, Sweden. His research interests are the intertwining of the technological and epistemic in the biosciences and education. His current research highlights the performativity of values and valuations in the science and technology of proteomics and biomarkers. 